\title{
Jesús, la persona del Hijo
}

\author{
Gonzalo Zarazaga \\ FACULTAD DE TEOLOGÍA DE SAN MIGUEL (ARGENTINA) \\ gzarazaga@jesuitas.org.ar
}

Resumen: La cristología ha sido la búsqueda permanente por expresar la verdadera identidad de Jesús. En la resurrección nos fue revelado que era Dios mismo quien actuaba nuestra salvación en la vida, la obra y la persona misma de Jesús. La fe en Jesucristo pronto se convirtió en la confesión de su identidad de Hijo de Dios, verdadero Dios y verdadero hombre. Sin embargo, no siempre se logró articular bien ambas dimensiones. El intento de expresar esa realidad en conceptos metafísicos, acarreó muchas veces la tendencia a supeditar la humanidad a la divinidad del Logos. La enhipostasía llevó a pensar en un Jesús que no era persona humana. La cristología del s. XX emprendió una profunda revisión de esos supuestos. La cristología de W. Kasper, Jesús el Cristo, afrontó el desafío de mostrar cómo, puede hablarse de persona humana de Jesús sin contradecir con ello el dogma cristológico. Puso así las bases para un nuevo gran consenso en la cristología contemporánea.

Palabras clave: Cristología, persona, humanidad, relación, acto, filiación, consenso.

Abstract: Christology has been the constant search to tell the real identity of Jesus. In the Resurrection it was revealed it is God himself who operates our salvation in the life and person of Jesus. The faith in Jesus Christ soon became the confession of his identity as the Son of God, true God and true man. Although, it was not always easy to articulate both dimensions, attempts to express this reality in metaphysical concepts subordinated the humanity to the divine nature of the Logos. The enhypostasis led to belief that Jesus was not a human person. W. Kasper's Jesus the Christ, faced the challenge of demonstrating how, it is possible to talk about the human person of Jesus without contradicting the Christological dogma. This way, Kasper laid the foundation for a new consensus in the contemporary Christology. Keywords: Christology, person, humanity, relation, filiation, consensus 
La historia de la teología ha estado marcada por la periódica reaparición de las grandes cuestiones cristológicas. Si los concilios ecuménicos de los siete primeros siglos de la era cristiana tuvieron un sello tan decididamente cristocéntrico, ello se debe a que en la pregunta por la identidad última de Jesús se juega el misterio nuclear de la fe de la Iglesia y su impronta trinitaria. Es en Jesús y por Jesús que se nos revela el Dios trino en que creemos. Si en el mismo NT encontramos diversidad de títulos cristológicos y perspectivas "de arriba" y "de abajo", es porque con la misma experiencia pascual nació la pregunta por la relación última entre Jesús y el Dios que él predicaba como presente y actuante en el mundo a través de su propia presencia y acción personal.

El NT es precisamente el testimonio de cómo a través de esa pluralidad de perspectivas cristológicas, las primeras comunidades cristianas fueron dando respuesta a la pregunta por la persona de Jesús como la cuestión básica y fontal de su fe ${ }^{1}$. Ya allí, distintos modelos de interpretación, distintas expresiones cristológicas, fueron surgiendo como modos de explicitación de una misma experiencia apostólica originaria de salvación en el encuentro con la persona, la vida, la obra y la palabra de Jesús, y su presencia resucitada por la acción del Espíritu en medio de los creyentes. Esa convicción básica de la fe fue el suelo firme que permitió que diversas perspectivas cristológicas fueran complementándose y armonizándose progresivamente en la búsqueda de explicitar la fe trinitaria de la Iglesia.

Esa búsqueda (y la diversidad que le es inherente) no podía detenerse por ello en el NT. Desde las primeras desviaciones docetas, pasando por la teología de Arrio, las apasionadas disputas entre el modelo ciriliano y el de nestorio, las propuestas monofisitas y monoteletas, la vuelta al Jesús histórico, las distintas versiones de Jesús de las cristologías liberales, la reacción existencial de Bultmann y su repercusión en el planteo de la New Quest y la Third Quest, hasta los debates en torno a la conciencia

"Hoy día es un dato unánimemente aceptado la existencia y legitimidad de una pluralidad de cristologías neotestamentarias y, por ende, de cristologías teológicas". O. González de Cardedal, Jesús de Nazaret. Aproximación a la cristología (BAC, Madrid ${ }^{2}$ 1978) 237. Los diferentes títulos dados a Jesús en la liturgia, la confesión de fe y la catequesis en las primeras comunidades, la coexistencia de una perspectiva cristológica más de ascenso y otra más de descenso, de una cristología más funcional y otra más ontológica, etc., son el testimonio de esta variedad de perspectivas en que se fue explicitando la única fe de la Iglesia. 
y el yo psicológico de Jesucristo, reflejan siempre la búsqueda por comprender y explicitar mejor el fundamento último de la fe en la respuesta por la identidad última de la persona de Jesús.

En síntesis, la pregunta en torno a quién fue este Jesús al que la Iglesia confiesa como el Cristo, Hijo de Dios y Salvador universal, es la cuestión central más propia de la fe cristiana y se encuentra ya en su mismo origen. Podría decirse que, según los sinópticos, el mismo Jesús la planteó como centro y desafío, teológico y existencial, de la vida espiritual del discípulo: “¿Y ustedes? ¿Quién dicen que soy yo?” (Mt 16, 15; Mc 8, 29, Lc 9, 20)2.

Más allá de los errores y desviaciones que caracterizaron muchas de esas búsquedas y posturas, fue a través de estos debates que la Iglesia fue discerniendo su fe, su auténtica comprensión de la realidad de Jesucristo como el lugar donde Dios ha ofrecido y realizado definitivamente su entrega como salvación para los hombres.

Sin embargo, el NT, porque brota de la experiencia de Dios hecha en la relación personal de los discípulos con el hombre Jesús, no se pregunta (a diferencia de lo que acontecerá en la cristología posterior) por la verdadera humanidad de Jesús. Ello resultaba del todo evidente. El hombre Jesús de Nazaret era el dato primario incontrastable. Como afirma W. Kasper: "El hecho de que Jesús de Nazaret fue un hombre verdadero es para el nuevo testamento algo que se presupone con toda naturalidad". La humanidad de Jesús no es algo que haya que descubrir o demostrar. Por ello, el NT no se detiene en mostrar detalles cotidianos de su biografía. Lo que en verdad le interesa señalar es "el significado salvífico de este verdadero ser hombre" 3 . Por eso mismo en el NT no se encuentra nunca una atribución directa de la divinidad a Jesucristo en una afirmación del tipo "Jesús es Dios” ${ }^{4}$ que se prestara a una identificación lisa y llana del hombre Jesús con Dios, o permitiera pensar en una "mezcla" de Dios y hombre. Ello hubiera implicado, por un lado, una antropo-

2 Es la pregunta cristológica por excelencia. Cf. J. DuPUIS, Introducción a la cristología (Verbo Divino, Pamplona 1994) 5.

3 W. Kasper, Jesús, el Cristo (Sígueme, Salamanca $\left.{ }^{9} 1994\right) 24$.

4 "Pues Jesús en y según su humanidad, que nosotros vemos cuando decimos "Jesús", no es Dios, y Dios en y según su divinidad no "es" hombre en el sentido de una identificación real". K. RAHner, Curso fundamental sobre la fe (Herder, Barcelona $\left.{ }^{3} 1984\right), 340$; K. Rahner-W. ThüsInG, Cristología. Estudio teológico y exegético (Cristiandad, Madrid 1975) 59. Cfr. también O. GonzÁlez de Cardedal, Jesús de Nazaret, 407. 
morfización mitológica de Dios, y por otro, una negación de la evidente constitución auténticamente humana del histórico Jesús de Nazaret. Lo que necesitaban dilucidar los discípulos no era en qué sentido Jesús era un hombre sino, por el contrario, el por qué y el cómo de la presencia y la acción del mismo Dios en y a través de este hombre concreto que era Jesús de Nazaret. Un hombre que ha resucitado y ha sido confirmado por Dios como salvador universal, único, definitivo y glorificado a la derecha del Padre.

En tal sentido, puede afirmarse que desde el comienzo mismo de la cristología en el NT es la convicción soteriológica la que impulsará la profundización de la comprensión en torno a la persona de Jesús 5 .

Ahora bien, si esta pregunta soteriológica central de la cristología por la identidad última de Jesús ha dado lugar ya en el NT a una diversidad de perspectivas, modelos y títulos cristológicos, ello se debe a que esa misma pregunta se plantea de muy diversas maneras según el ámbito histórico y cultural en el que surge y se explicita ${ }^{6}$. Las diferencias teológicas de enfoque entre los distintos evangelios sinópticos, la cristología de Pablo o de Juan, no provienen de diferencias en la fe, sino que se fundan en las diferentes situaciones vivenciales de la comunidad, distintos ámbitos históricos y culturales, anclados en mundos lingüísticos y conceptuales con características propias ineludibles. Por ello, si luego tuvo lugar un proceso de cierta helenización del dogma, ello no debe interpretarse necesariamente como una desvirtuación de la fe cristológica, sino como el resultado propio de la búsqueda evangelizadora y teológica, de una mejor explicitación y difusión de la fe en una realidad histórica y cultural determinada. El proceso mismo de adaptación conceptual tuvo por fin

5 "Conceptualmente conviene distinguir entre la cristología propiamente dicha y la soteriología. Pero de hecho estos dos aspectos están íntimamente ligados en el desarrollo del dogma. La motivación misma de los debates cristológicos era soteriológica. La cuestión seguía siendo: ¿quién tiene que ser Cristo para que pueda ejercer la mediación única entre Dios y los hombres que le reconocen las Escrituras?”. B. SesboüÉ, El Dios de la Salvación (Secretariado Trinitario, Salamanca 1995) 269.

6 "Cada órbita lingüística, cada órbita cultural, cada órbita religiosa, cada tipo de pensamiento, cada talante humano induce una esperanza nueva y un interrogante distinto a la figura de Jesús". Precisamente, "esta radical trascendencia de Cristo sobre la historia es lo que le confiere su radical capacidad de inmanencia en cada cultura”. O. González de Cardedal, Jesús de Nazaret, 229s. 
inculturizar la fe, pero preservándola de las tergiversaciones que podían imponerle los aspectos incompatibles de otros modelos cosmológicos.

Fue así que en el contexto de las disputas arrianas, Nicea se sintió inclinada a definir con firmeza la identidad divina de Jesús. Un siglo más tarde, Calcedonia, en cambio, creyó necesario, ante las nuevas tendencias monofisitas, sostener ahora con igual determinación la identidad humana de ese mismo Jesús.

De esa manera, la pluralidad de cristologías del NT se prolongó, de alguna manera, en las diversas miradas y acentos de Nicea y Calcedonia, de la escuela alejandrina y la antioquena, continuó en los debates en torno a cómo entender la voluntad de Jesús, su ciencia y su conciencia, para reaparecer siglos después en la problemática del Jesús histórico y el Cristo de la fe. El aporte de toda esa discusión cristológica de siglos, fue el de volver a poner al descubierto, una y otra vez, tanto el peligro de reducir a Jesús a un héroe más de la historia de la humanidad como el de comprenderlo como un Dios disfrazado de hombre, que se pasea brevemente por la tierra, con un plan ya cerradamente predeterminado y acabado, que no depende de la historia ni de las decisiones humanas para la ejecución de la salvación. A lo largo de esas discusiones, las respuestas complementarias de Nicea y Calcedonia se transformaron en el fundamento y criterio regulador de la cristología. La verdadera humanidad y divinidad de Jesucristo debían preservarse siempre, sin anularse ni disolverse la una en la otra.

Se debe reconocer, sin embargo, que hubo largos períodos históricos en que ese equilibrio entre humanidad y divinidad de Jesús trabajosamente alcanzado por la historia que va de Nicea a Calcedonia se vio de nuevo fuertemente desbalanceado.

En la historia de la piedad cristiana con frecuencia se sublimó y divinizó tanto la figura de Jesús, que para la conciencia eclesiástica corriente apareció como un Dios que se paseaba por la tierra, oculto tras el adorno y librea de una figura humana, pero cuya divinidad "resplandece" una y otra vez, mientras que se ocultan detalles pertenecientes a la "banalidad" humana. Fundamentalmente apenas si se podrá decir, que la doctrina de la verdadera humanidad de Jesús y su significado salvífico haya penetrado profundamente en la conciencia corriente de los cristianos. En el fondo se encuentra aquí, 
con frecuencia, una concepción de Jesucristo sumamente mitológica y docetista ${ }^{7}$.

Una y otra vez emerge por ello, de manera siempre nueva, la problemática sobre cómo comprender (y explicar) la realidad divino-humana de Jesús en un nuevo contexto epocal. Obviamente, no basta con yuxtaponer ambas dimensiones en un paralelismo estático. Nuevas sensibilidades, nuevas perspectivas e imaginarios culturales requieren por ello hoy volver a explicitar la identidad última de Jesús en el propio lenguaje, de una manera más dinámica, histórica y antropológicamente integrable.

El misterio insondable de Cristo exige siempre de la fe nuevas profundizaciones y explicitaciones teológicas que, sin apartarse de las verdades dogmáticamente establecidas, puedan vislumbrar mejor la identidad de Jesucristo, brindando una articulación más dinámica y profunda de su humanidad y su divinidad, en cada nuevo contexto histórico y cultural. Es precisamente en este punto que la cristología del siglo XX parece haber alcanzado un nuevo espacio de consenso en torno a la necesidad de buscar una visión más integral, armónica y realista de humanidad y divinidad de Jesucristo. En lo que sigue, intentaremos mostrar cómo a través de un nuevo consenso en la recepción de Calcedonia (1), y en torno a la propuesta fundamental de Walter Kasper $(2)^{8}$, se fue gestando un nuevo consenso (3) que distingue con un sello distintivo a la cristología contemporánea, en medio de una rica diversidad de perspectivas teológicas.

7 W. Kasper, Jesús, el Cristo, 245, ver también 260. El monifisismo de Eutiques y la disputa monoteleta son solo los emergentes más graves de esta tendencia. Ya K. RAHNER había advertido sobre el peligro de un latente monofisismo en la cristología católica, "Problemas actuales de cristología", en Escritos de Teología I (Taurus, Madrid 1963) 208s. G. Uríbarri, en cambio, sostiene que ese "peligro de criptomonofisimo" ya "ha quedado completamente superado" y que hoy estamos ante el peligro inverso de descuidar la divinidad de Jesús. La singular humanidad de Jesucristo (San Pablo-Comillas, Madrid 2008) 95, también 63, 93 y passim. En todo caso, parece más bien que ambos peligros han continuado siempre presentes y en tensión en la historia de la teología. Tal vez, se trate de una tensión inherente a la pregunta cristológica de cómo dar cuenta del misterio de Jesucristo como verdadero Dios y verdadero hombre; consubstancial con nosotros y consubstancial con el Padre.

8 La idea de este artículo surgió en el año 2013 en el contexto de la celebración de los 80 años de vida del cardenal W. KASPER y en vísperas de la celebración en el año 2014 de los 40 años de la aparición de su famosa cristología Jesús, el Cristo, que hemos venido citando. 


\section{CONSENSOS EN TORNO A CALCEDONIA}

Una de las fuentes de que se nutrió el surgimiento de los nuevos consensos cristológicos ${ }^{9}$ en el siglo XX fue la profunda revisión de los verdaderos alcances, aportes y límites del Concilio de Calcedonia ocurrida fundamentalmente en torno a los 1500 años de la celebración de aquel concilio $^{10}$. Esa reflexión permitió volver a tomar conciencia no solo de que la principal intención del concilio fue la de rescatar la auténtica humanidad de Jesucristo frente al peligro de una reducción monofisita, sino, sobre todo, que la doctrina del concilio debía distinguirse claramente de algunas lecturas neocalcedonianas que fueron producto de una interpretación posterior. En concreto, la renovación de los estudios sobre Calcedonia permitió comprender que la doctrina de la anhipóstasis, según la cual la naturaleza humana de Jesucristo carece de personeidad propia por estar enhispostasiada en la persona divina del Verbo, dista de mucho de ser una lectura obligada del Concilio ${ }^{11}$. Es más, si la intención del

9 Obviamente, hablar de consenso no implica aquí absoluta unanimidad. Solo afirmamos que existe una importante concordancia entre los especialistas, como se podrá observar en el aparato crítico de este trabajo.

10 Tal vez una de las obras más significativas en esta línea haya sido la de los tres tomos de estudios reunidos por A. Grillmeier - H. BACHT (eds.), Der Glaube von Chalkedon. Geschichte und Gegenwart (Echter, Würzburg 1951-1954). Allí, en el Tomo III, aparecía el famoso artículo de K. RAHNER, "Chalkedon - Ende oder Anfang?”, 3-49, llamado a alcanzar una gran repercusión y consenso y que ya hemos citado en su versión en español, "Problemas actuales de cristología", 169-222.

11 De hecho, el concepto enhipóstasis no se encuentra en Calcedonia ni tampoco directamente en Contantinopla II. Se trata de una interpretación formulada por Leoncio de Bizancio. Cf. P. Schoonenberg, Un Dios de los hombres (Herder, Barcelona 1972) 66s.; B. Sesboüé, El Dios de la salvación, 333ss.; W. Kasper, Jesús, el Cristo, 297. Si bien la doctrina de la enhipóstasis podía resultar una lectura consecuente de Constantinopla II, la afirmación lisa y llana de una naturaleza humana anhipostática implicaba ir más allá de lo que los concilios se habían atrevido a afirmar explícitamente. Pero poco a poco, bajo el predominio de una cristología marcadamente de descenso, la doctrina de la enhipóstasis se fue imponiendo en un sentido cada vez más marcadamente anhipostático. Esta tendencia perduraría a pesar de los esfuerzos del Concilio de Constantinopla III por sostener decididamente una conciencia, una libertad y una voluntad propiamente humanas en Jesús. Cf. J. DupuIs, Introducción a la cristología, 162ss. Fueron importantes aquí las reflexiones de W. Pannenberg, Fundamentos de Cristología (Sígueme, Salamanca 1974) 420428. Para un estudio específico sobre la doctrina de la enhipóstasis, ver G. EssEN, Die Freiheit Jesu. Der neuchalkedonische Enhypostasiebegriff im Horizont neuzeitlicher Subjekt- und Personphilosophie (Friedich Pustet, Regensburg 2011). 
Concilio fue en realidad defender la identidad plenamente humana de Jesús, esta interpretación posterior pareció venir a debilitarla.

Ahora se convirtió en opinio communis en teología [...] que la naturaleza humana no tiene hipóstasis humana propia, sino que subsiste en la del Logos. A pesar de todas las precauciones en esta teoría latía el peligro de que, por una parte, se recortaba la naturaleza humana $y$, por otra, se convertía al Logos en un principio intramundano ${ }^{12}$.

Obviamente, si las discusiones cristológicas continuaron es porque Calcedonia no pudo terminar de aclarar todas las dudas ${ }^{13}$. El problema fundamental fue que la fórmula del Concilio puso la complementariedad humano-divina en el nivel de las naturalezas, pero no terminó de explicitarla a nivel de la persona concreta y única de Jesús. El Concilio, en su búsqueda de alcanzar cierto nivel de consenso, debió conformarse con trazar límites negativos más allá de los cuales comenzaría a traicionarse el anuncio del NT.

La distinción entre naturaleza y persona es, ante todo, no más que una solución terminológica de emergencia. Especialmente los conceptos de persona e hipóstasis en Calcedonia estaban muy lejos de ser precisos [...] Por eso se conforma el concilio con delimitar la fe contra los errores de derecha e izquierda. No pasa de una declaración de su fórmula mediante cuatro conceptos negativos: «sin mezcla, sin cambio, sin separación ni división». O sea, el concilio no formula teoría alguna metafísica sobre Cristo, sino que se para en una christologia negativa que mantiene el misterio ${ }^{14}$.

12 W. Kasper, Jesús, el Cristo, 294. Por eso mismo Juan Damasceno, en su De la Recta fe III, 9, intentaba explicar la teoría de la enhipóstasis evitando los peligros algo monofisitas de una compresión anhipostática demasiado unilateral: "Puede ocurrir que concurran (las dos naturalezas) en una hipóstasis y entonces ni son anhipostáticas ni tiene cada una su propia hipóstasis, sino que ambas tienen una y la misma”. Citado por G.L. Müller, Dogmática (Herder, Barcelona 1998), 351.

13 En realidad: "Calcedonia estuvo lejos de alcanzar inmediatamente un consenso unánime. Puede decirse incluso que su fórmula "engendró un cisma del lenguaje (J. Moingt) abierto no solamente entre herejes y ortodoxos, sino entre los propios ortodoxos entre sî". B. SEsboüé, El Dios de la Salvación, 324.

14 W. Kasper, Jesús ... 291s. Lo ratifica la Comisión TeOlÓgica Internacional cuando afirma: "La definición dogmática de Calcedonia no pretende dar una respuesta exhaustiva a la pregunta: ¿Cómo pueden coexistir Dios y el hombre en Cristo? En eso consiste el misterio de la encarnación. Ninguna definición puede agotar sus riquezas por medio de fórmulas afirmativas. Conviene, más bien, proceder por 
Así como la fe neotestamentaria confiesa dinámicamente, a través del acontecimiento Pascual, la identidad del resucitado con el crucificado, del Cristo glorioso con el histórico Jesús de Nazaret y sin embargo no alcanza a explicar ontológicamente el paso de la muerte a la nueva vida; de la misma manera la cristología debía poder confesar el evento de la fe cristológica como basada en la identidad del Logos inmanente con el económico, del Hijo preexistente con el Hijo encarnado en el Jesús de la historia, sin pretender explicar del todo el cómo de ese misterioso salto ontológico $0^{15}$ que permite la identidad de la persona del Hijo en la diferencia de las "naturalezas". Es esta imposibilidad de una mayor explicación "ontológica" última de la identidad en la diferencia la que reconoce negativamente la fe de Calcedonia con el indivise et inconfuse.

No es entonces que nada quede definitivamente afirmado: Calcedonia logró establecer que es esencial a la fe confesar a Jesucristo como verdadero Dios y como verdadero hombre en la unidad de un único sujeto, aunque no haya podido terminar de explicar el cómo de esta unidad de dos esencias distintas en la única persona de Jesús. El concilio solo advierte contra falsas explicaciones a partir de los cuatro famosos conceptos negativos: sin mezcla, sin cambio, sin separación, sin división. Pero las dificultades son obvias a la hora de intentar formular positivamente qué significan estas determinaciones para la persona única, real y concreta de Jesús de Nazaret. El escollo proviene en gran parte del intento de fijar en una formulación estática y abstracta lo que el NT había proclamado de forma dinámica de la persona concreta $^{16}$. El cambio de para-

la vía de la negación, y trazar un espacio del cual no es lícito alejarse”. Cuestiones selectas de cristología (1979), II.6.

15 "La fórmula alejandrina se fijaba en primer término en el Logos divino, en su physis única en Dios. Y al añadir la palabra encarnada, mostraba a este Logos en su saltus Amoris, en su salto a la realidad de la carne y de la tierra. Esta fórmula es solo una paráfrasis de Jn 1,14; el Logos se hizo carne; es decir, su physis una e indivisible se hizo carne, y sigue siendo la misma physis única en esta realidad de la carne... para que la fórmula de Calcedonia no conduzca a una visión unilateral de Cristo, es necesario completarla con el dinamismo de la visión alejandrina y ciriliana”. A. GrillmeIER, "La imagen de Cristo en la teología católica actual", en J. FEINER - J. TRÜTSCH - F. Böckle (eds.), Panorama de la teología actual (Guadarrama, Madrid 1961), 346.

16 Dice A. Grillmeier que "Por ello se adhirieron tan fuertemente los griegos, antes y después de Calcedonia -cuya fórmula cristológica tiene un tinte estático-, a la afirmación central alejandrina: 'Una es la naturaleza encarnada del LogosDios'. Porque si no la consideramos solo como opuesta a Calcedonia, la fórmula alejandrina expresaba un acontecimiento, más aún, expresaba toda la 'oikonomía' 
digma ocurrido de los modelos mentales bíblicos al esquema ontológico del pensamiento helenista trajo consigo, junto con una mayor precisión terminológica y conceptual, esta dificultad del pensamiento metafísico.

El desafío de la cristología es entonces ahora intentar pensar de una forma más positiva, dinámica e histórica la misma verdad de fe que Calcedonia intentó expresar en una teología negativa con términos algo estáticos.

Con ello, la crítica de Calcedonia se transformó, a su vez, en un relanzamiento de su intención más profunda. Si fueron las disputas posteriores al concilio las que condujeron a un nuevo fortalecimiento de una tendencia algo neomonifisita ${ }^{17}$, contraria al propio deseo de ese concilio de reafirmar la consustancialidad humana de Jesús (al mismo nivel que Nicea había afirmado su consustancialidad divina); la revisión crítica de Calcedonia impulsó en el siglo XX una renovada conciencia cristológica de la inclaudicable confesión de la humanidad plena de Jesús. Porque el Verbo no asumió solo la naturaleza humana, en sentido abstracto y general, sino que asumió mucho más concretamente el hacerse hombre, encarnarse y nacer verdaderamente como un hombre real, concreto, único e irrepetible, con libertad y conciencia humanas propias (tal como fue definido por el Concilio III de Constantinopla) ${ }^{18}$, desplegándose en todo como un ser humano libre, autónomo, en una historia humana, propia y personal.

realizada en Cristo, y hacía brillar, como un meteoro que cae, la gloria de Dios aparecida en Cristo". "La imagen de Cristo...”, 346.

17 Las discusiones poscalcedónicas, duras e intensas, desembocaron en el polémico Concilio II de Constantinopla que optó por una lectura más alejandrina de Calcedonia aunque, paradójicamente, acentuando que "si el sujeto último de las actividades de Cristo es ciertamente el Verbo, no lo es nunca el Verbo solo, sino siempre el Verbo en cuanto persona humanizada". B. Sesboüé, El Dios de la salvación, 335. El subrayado es nuestro.

18 "Es un hombre que vivió en un contexto concreto y que murió después de haber llevado su propia existencia dentro de la evolución de la historia. La investigación histórica sobre él es, pues, una exigencia de la fe cristiana... Hoy en día es fructífero y necesario, en el campo de la teología dogmática, un retorno hacia el Jesús terrenal, dentro del marco más amplio que queda indicado. Es sumamente importante poner en evidencia las innumerables riquezas de la humanidad de Jesucristo, y más de lo que lo hicieron los cristologías del pasado". Comisión Teológica InTERnacional, Cuestiones selectas de cristología (1979) I.1 y I.2.6. 
Así, una vez más, la pregunta por cómo entender hoy este hacerse hombre del Hijo de Dios volvía a manifestarse abierta y desafiante en el contexto de una nueva realidad cultural. Calcedonia mostraba no haber puesto punto final a la cristología sino, muy por el contrario, haberse convertido en un sólido fundamento del cual volver a partir ${ }^{19}$. Sobre la base de un nuevo gran consenso en la recepción crítica de Calcedonia ${ }^{20}$ y la importancia de su significado para volver a pensar más cabalmente la humanidad de Jesús como el lugar teológico donde se revela su divinidad, se fundarían muchos de los intentos de la cristología contemporánea.

La búsqueda del Jesús histórico, el proyecto de desmitologización, o la perspectiva de un Jesucristo comprometido y liberador, más allá de las críticas que pudieron justamente merecer, pueden ser comprendidas desde una renovada conciencia y sensibilidad que buscaba rescatar de las sombras, como ya lo hiciera Calcedonia, la auténtica humanidad del hombre Jesús.

\section{REPENSAR LA PERSONA DE JESÚS}

Esta mirada que buscaba volver a rescatar la humanidad de Jesús y su historia personal concreta como fundamento real de la fe de los primeros discípulos, fue la que reanimó el debate cristológico desde las perspectivas propias del pensamiento moderno. En la teología católica, la discusión en torno a la identidad personal de Jesús se fue desplazando así desde los enfoques metafísicos propios de la escolástica hacia una perspectiva más fenomenológica e histórica.

19 Cf. el famoso artículo ya citado de K. RAHnER, "Problemas actuales de cristología?", 169-222.

20 Sin pretender ser exhaustivos, algunos testimonios contemporáneos significativos de este consenso básico pueden rastrearse en A. Grillmeier - H. BACHT (eds.), Der Glaube von Chalkedon; W. PANnENBerG, Fundamentos de cristología (Sígueme, Salamanca 1973) 351-356; W. Kasper, Jesús, el Cristo, 290-294; B. SesboüÉ, El Dios de la Salvación, 323s.; "Le procés contemporain de Chalcédoine", en RSR 65 (1977) 45-79; J. DupuIs, Introducción a la cristología (Verbo Divino, Pamplona 1994) 173ss.; O. GonzÁlez de Cardedal, Cristología (BAC, Madrid 2001) 271ss. esp. nota 243; H. Kessler, "Cristología", en Th. Schneider (Dir.), Manual de Teología Dogmática (Herder, Barcelona 1996) 412ss.; J.I. GonZÁlez Faus, Fe en Dios y construcción de la historia (Trotta, Madrid 1998) 104ss.; La humanidad nueva. Ensayo de Cristología (Sal Terrae, Santander 1984) 434, 455-471. 
La encíclica Sempiternus Rex, conmemorando el 1500 aniversario del concilio de Calcedonia, reconocía expresamente como justo el deseo de investigar la realidad humana de Jesús [...] pero dejaba claro que la definición de Calcedonia no permite admitir en Cristo dos individuos [...] La encíclica, por el contrario, dejaba abierta la cuestión de si es posible reconocer un sujeto humano psicológico relativamente independiente ${ }^{21}$.

Pero precisamente, reconocer a Jesús como un sujeto humano psicológico independiente, que se percibe y se dice a sí mismo como hombre, que se manifiesta fenoménicamente en el mundo con una identidad humana propia, concreta y singular, es precisamente lo que en el plano antropológico se comprende hoy como un sujeto humano real sin más. El desafío consistía entonces en explicar esa real existencia de Jesús como sujeto humano pero sin traicionar el principio calcedoniano de no dar lugar ni a una duplicación de sujetos en Cristo, ni a ignorar su divinidad. ¿Afirmar que Jesús de Nazaret es un sujeto humano real no implicaría negar que él sea una persona divina? ¿Afirmar que es realmente un sujeto humano y también divino no forzaría a una nestoriana duplicación de sujetos? Está claro que el dogma cristológico advierte contra esos dos errores fundamentales.

En el ámbito de la teología católica, fue a mi entender Walter Kasper quien consolidó algunas de las principales claves para perfilar una solución que parece haber ido alcanzando un consenso cada vez mayor. Recogiendo algunas grandes intuiciones de K. Rahner y corrigiendo otras de P. Schoonenberg, Kasper formularía algunas de las afirmaciones más audaces de la cristología contemporánea. Su propuesta está fundada en la convicción de que "tenemos que hacer hoy algo parecido a lo que realizaron los concilios de la antigua Iglesia para su tiempo", y hacerlo "ayudándonos de los medios intelectuales de hoy"22, que pueden impulsar al teólogo "a tener en cuenta el acontecimiento de Cristo mejor de lo que le era posible a la tradición de impronta metafísica, y a pensar a Dios no abstracta y filosóficamente, sino en concreto como el Dios y Padre de Jesucristo"23.

Ya se encuentra aquí una primera clave que no debemos soslayar: la comprensión de la identidad última de Jesucristo no debe ser buscada hoy a partir de una deducción de su constitución ontológica y su expresión en una

\footnotetext{
21 W. Kasper, Jesús, el Cristo, 300.

22 W. KaSPER, Jesús, ... 225.

23 W. Kasper, Jesús, ... 228. Subrayado nuestro.
} 
fórmula estática de tipo metafisico, sino en el acontecimiento de la manifestación de su persona en la historia, en permanente referencia al Padre, es decir, en su carácter de Hijo. Por eso mismo, ya "en el nuevo testamento se fue imponiendo cada vez más un título a todos los demás; se vio que era el más adecuado y el más fructífero: Jesús, el hijo de Dios". Ese título "expresa lo esencial y específico de la totalidad de la fe cristiana" ${ }^{24}$.

Kasper se fija sobre todo en dos textos centrales para la cristología del NT: el himno de Fil 2, 6-11 y el prólogo del Evangelio de Juan. En ambos se trabaja con la idea de un único sujeto del que se predican dos modos de existencia distintos ${ }^{25}$. Es el mismo Hijo, el mismo Logos que existía junto al Padre y era de condición divina, quien se abaja y asume una nueva realidad. Pero la asume no sumándola, por así decirlo, a su naturaleza divina originaria sino abajándose, deviniendo en la condición de siervo, deviniendo verdaderamente carne, asumiendo una nueva realidad como hombre mortal (sarx), naciendo de un modo nuevo en la carne como realidad creada. Es este dinamismo de la perspectiva histórico-soteriológica la que no debe perderse de vista cuando se quiere comprender lo que Calcedonia intentó defender con la afirmación de dos naturalezas ${ }^{26}$. No se trataba de afirmar dos componentes estáticos que no se mezclan, no se confunden, pero tampoco se articulan. Lo que se buscaba en Calcedonia era mantener la unidad del único Logos, el único Hijo de Dios que deviene hombre en la carne de Jesús sin perder nunca su identidad de Hijo único del Padre.

La afirmación de la preexistencia de este Hijo en el seno de Dios no es en el nuevo testamento una formulación de tipo metafísico, sino de tipo soteriológico. No pretende establecer cuál era la esencia metafísica de Jesús antes de nacer. Como si el hombre Jesús pudiera tener, a diferencia de los demás hombres, alguna existencia que fuera anterior a su propio nacimiento. No es Jesús quien preexiste a sí mismo sino el Logos, la persona del Hijo de Dios ${ }^{27}$. Lo que se intenta es hallar el fundamento

24 W. KASPER, Jesús, ... 199.

25 W. Kasper, Jesús,... 283-285.

26 "Aun siendo, pues, el dogma de Calcedonia exégesis perennemente obligatoria de la Escritura, tiene que ser integrado, sin embargo, también en el testimonio global bíblico y se ha de interpretar a partir de este”. W. KASPER, Jesús, ... 292.

27 Aportan importantes reflexiones para una más profunda comprensión del tema de la preexistencia W. Pannenberg, Fundamentos de cristología,165-208 y J. Moingt, El hombre que venía de Dios (Desclée de Brouwer, Bilbao 1995) II, 271 ss. 
del acontecimiento salvífico que ha tenido lugar a través de la vida, la muerte y resurrección de Jesús que se ha manifestado entendiéndose a sí mismo como el hombre que es el Hijo muy querido, el unigénito enviado por el Padre.

Para captar en toda su profundidad el significado de esta referencia insoslayable de Jesús al Padre es necesario comprender también desde nuevas coordenadas qué significa ser persona. La concepción de la persona ha sufrido una profunda transformación en la fenomenología y el personalismo contemporáneo. Ella no debe ser ya pensada desde la primacía de las categorías de sustancia, individualidad o hipóstasis, sino desde y en su radical apertura y constitución relacional ${ }^{28}$. La persona no es fundamentalmente una substancia individual per se, que luego, casi aleatoriamente, establece relaciones; no es un individuo constituido aisladamente en una ipseidad estática ya acabada desde el comienzo; no es un sujeto que luego actúa como centro de actos derivados. Estas tendencias habían llevado a la filosofía moderna a pensar en el sujeto trascendental como centro, fuente y criterio de la realidad. Por el contrario, la idea bíblica de la creación implica una comprensión distinta, más relacional y extática, que implica provenir de otro y existir en virtud de otro. La persona es el existente que se constituye y se percibe a sí mismo solo en cuanto apertura y relación con lo otro en cuanto real. La alteridad plural de la creación es un elemento constitutivo de la realidad personal. Una alteridad que remite al Creador. "El hombre no puede sacar de sí mismo las líneas fundamentales de su existencia". "El ser humano es existencia receptora, ser que se debe a otro" ${ }^{29}$. No hay personas sin comunicación interpersonal ni hay comunicación plural sin personas. La persona es la existencia que alcanza su identidad en el intercambio de recepción y donación con los otros en cuanto reales y en cuanto personas, en la comunicación plural con la alteridad ${ }^{30}$.

28 La idea de persona como relación no es nueva. Se trata de una línea iniciada ya por los Capadocios, continuada por Agustín y profundizada por Santo Tomás. Ellos indagaron en la relación como manera de acceder a una comprensión de persona aplicable a la Trinidad. Con todo, se trataba de una idea todavía supeditada al primado del pensamiento substancial. Solo en la substancia única es que ellas pueden darse relaciones que sub-sisten como hipo-stasis.

29 W. Kasper, Jesús, ... 263.

30 Hemos presentado ya en distintos trabajos cómo el concepto de persona ha evolucionado en el pensamiento contemporáneo, aquí solo nos referimos muy brevemente a ello sin desarrollarlo en profundidad. Ver G. Zarazaga, Dios es 
Ahora bien, esta característica de la constitución relacional-comunicativa del ser personal se verifica de una manera sobreeminente en la vida trinitaria. También la persona del Hijo está determinada desde su constitutiva relacionalidad ${ }^{31}$. La filiación constituye la identidad misma de la persona de Jesús. "Su esencia no consiste en existir como hipóstasis", como una autonomía cerrada, en sí y por sí, sino en la relación de filiación vivida como "autoentrega, autodonación"32. en obediencia al Padre y fraternidad con los hombres. Por ello, él se entiende y manifiesta como recibiendo siempre su existencia desde y hacia el Padre.

Comprender la persona de Jesús en base a su dinámica relación de filiación con el Padre, libera de tener que entenderla desde una suerte de composición sin mezcla de dos naturalezas algo estáticas, casi extrañas e incompatibles, y que terminan diciendo poco tanto de la humanidad como de la divinidad propia de la persona concreta de Jesús. La perspectiva relacional permite comprender de modo nuevo lo que Calcedonia quería señalar en el lenguaje de su tiempo: "que en Jesucristo Dios mismo se ha insertado en una historia humana, saliéndonos al encuentro en esta historia de un modo completo y totalmente humano"33.

En esta línea es que, como vimos, Kasper tomaba distancia de la teoría neocalcedónica de la enhipostasía ${ }^{34}$ y admitía razones para una defensa de la forma moderada de la teoría del homo-assumptus ${ }^{35}$. Al igual que en Calcedonia, era el peligro de un larvado monofisismo que llevara a negar la existencia de Jesús como verdadero sujeto humano concreto, lo que con aquella teoría se quería evitar. Por eso Constantinopla III volvió ratificar la necesidad de afirmar una libertad y voluntad auténticamente humanas en Jesús. Esta discusión es la que en el fondo volvería surgir en

comunión (Secretariado Trinitario, Salamanca 2004), 262ss., 302ss.; La Trinidad en el horizonte de la comunión, en Stromata 59 (2003) 113-142.

31 En G. Zarazaga, "Persona y humanidad del Hijo de Dios. Aportes teológicos en torno a la persona de Jesús", en Estudios Eclesiásticos 86 (2011) 3-37, hemos desarrollado más extensamente de lo que podremos hacerlo aquí, la importancia para la articulación entre naturaleza divina y humana de Jesús de concebir su persona a partir de esta clave dinámica, trinitaria y relacional.

32 W. Kasper, Jesús, ... 269.

33 W. Kasper, Jesús, ... 292.

34 Ver supra, nota 11.

35 W. KASPER, Jesús, ... 293. 
el siglo XX pero ahora en torno a la conciencia humana de Jesús ${ }^{36}$. No faltaba mucho para que esta temática de tono abstracto se trasladara a su fundamento real y concreto: una nueva consideración sobre la persona de Jesús.

Kasper refiere aquí a P. Schoonenberg como uno de los iniciadores de esta nueva perspectiva al intentar una inversión de la teoría de la enhipostasía, es decir, no es la naturaleza humana la que está enhipostasiada en la persona divina, sino la naturaleza divina del Logos la que se enhipostasía en la persona humana de Jesús ${ }^{37}$. De tal manera "que se puede hablar de una enhipostasía de Jesús en el Logos..., y viceversa, se puede hablar de una enhipostasía del Logos en el hombre Jesús"38. Kasper señala las deficiencias y ambigüedades (sobre todo trinitarias) que se descubren en la propuesta de Schoonenberg, pero asume el desafío de mostrar en qué sentido puede hablarse correctamente hoy de "persona humana” de Jesús sin traicionar la fe cristológica ni el dogma de Calcedonia: concretamente, sin negar su divinidad ni terminar adjudicándole una duplicidad de sujetos.

La clave para ello está en no partir de las expresiones de Calcedonia para desde alli deducir más consecuencias ontológicas para la realidad de Jesucristo. No era eso lo que el concilio pretendía. "En lugar de eso vamos a entender el dogma como interpretación de la realidad histórica de

36 Son importantes, entre otras, las contribuciones de: P. GaLTier, L'unité du Christ. Etre-personne-conscience (Beauchesne, París 1939); "La conscience humaine du Christ, à propos de quelques publicationes récentes”, en Gregorianum 32 (1951) 525-568; "La conscience humaine du Christ. Épilogue", en Gregorianum 35 (1954) 225-246; P. Parente, "Unità ontologica e psicologica dell'Uomo-Dio", en Euntes docete 5 (1952) 337-401; L'io di Cristo (Morcelliana, Brescia ${ }^{2} 1955$ ); A. Grillmeier, "La imagen de Cristo ...", 335-376; H. Diepen, "La psychologie du Christ selon saint Thomas d'Aquin", en Revue Thomist 50 (1950) 515-562; "L’unique Seigneur Jésus-Christ", en Revue Thomist 53 (1953) 28-80; J. Ternus, "Das Seelen- und Bewußtseinsleben Jesu. Chalkedon Problemengeschichtlichsystematische Untersuchung", en A. Grillmeier - H. BaCHT (eds.), Das Konzil von Chalkedon, III, 81-237; R. HauBst, "Welches Ich spricht in Christus?", en TTZ 66 (1957) 1-20; E. Gutwenger, Bewusstsein und Wissen Christi (Rauch, Innsbruck 1960); "Das menschlichen Wissen des irdischen Christus", en ZKTh 76 (1954) 170-186; K. Rahner, "Ponderaciones dogmáticas sobre el saber de Cristo y su consciencia de sí mismo", en Escritos de Teología V (Taurus, Madrid 1964) 221-243 (que trae abundante bibliografía sobre el tema).

37 Cf. P. Schoonenberg, Un Dios de los hombres, 99s, 102.

38 Citado por W. Kasper, Jesús, ... 301. 
Jesús y su relación con el Padre". "Nuestro punto de partida es el modo como se han revelado Dios y el hombre en la obediencia de Jesús para con su Padre y en su servicio por nosotros" ${ }^{39}$. Es allí, en la relación filial vivida como obediencia incondicional pero verdaderamente humana, libre y creada que se expresa el amor de Dios en la vida concreta de Jesucristo. Si Jesús es verdaderamente la presencia en medio de nosotros del amor de Dios mismo, es porque él, como hombre, en su realidad libre e histórica, realiza la mayor unidad del hombre con Dios y de Dios con el hombre, como relación y destino de filiación.

En concreto, la persona se realiza solo en relaciones [...] Por eso, la persona se encuentra solo en medio de una triple relación: consigo, con el mundo humano y con el mundo material. Se halla en sí, estando en el otro. Dicho en concreto: la esencia de la persona es el amor [...] Pero estas relaciones horizontales se cruzan, por así decir, son sostenidas por la relación total del hombre con $\operatorname{Dios}^{40}$.

Es en la conjunción de la relación vertical como recepción de sí desde Otro, con la relacionalidad horizontal con el conjunto de la alteridad de lo real y de cada otro, que cada persona es constituida como un yo insustituible, irrepetible, incomunicable y siempre concretamente situado en el ámbito de lo real. También la persona de Jesús, como toda persona, encuentra su fundamento y su identidad en la relación única e irrepetible con Dios y el conjunto de lo real en cuanto tal. Es aquí donde la referencia de Jesús al Padre, manifestada por él mismo como único fundamento de su vida y su identidad, descubre toda la profundidad de su sentido y dimensión propiamente trinitaria. "En realidad, la mediación entre Dios y el hombre en Jesucristo se puede entender solo en la perspectiva teológico-trinitaria” ${ }^{41}$. Fue precisamente en el ámbito de la teología trinitaria donde las grandes elaboraciones de los Capadocios, Agustín, Ricardo de San Víctor y Tomás de Aquino profundizaron la comprensión de las personas divinas desde la perspectiva relacional. Las personas divinas tienen su identidad en el seno perijorético de sus relaciones internas.

Así las cosas, lo propio de la persona del Hijo no es otra cosa que el decirse a sí mismo como entrega absoluta y filial al Padre de quien se

\footnotetext{
39 W. Kasper, Jesús, ... 301 y 302.

40 W. Kasper, Jesús, ... 303.

41 W. Kasper, Jesús... 309.
} 
recibe gratuitamente como Hijo. Esta referencia total de sí al Padre es la que puede expresarse como obediencia y entrega incondicional en la dimensión económica. Jesús no se comprende a sí mismo desde una vinculación personal con el Logos o con una vaga naturaleza divina. No hay testimonio de ello en las Escrituras. Jesús entiende toda su existencia desde el Padre, se entiende como su Hijo amado, que recibe su origen, su misión y su destino desde el Padre y solo puede vivir y realizar su identidad desde esta referencia, desde y en esta relación. Es así que expresa en su propia historia y realidad humana, su identidad de Hijo único del Padre.

Precisamente porque (y no: aunque) Jesús se sabía totalmente uno con el Padre, tenía al mismo tiempo, una conciencia absolutamente humana, hacía preguntas, crecía en edad y sabiduría (cf. Lc 2, 52). Su conciencia de unidad con el Padre no era pues, un saber objetivo, sino una especie de existencia y orientación fundamental que adquiría su concreción en las situaciones siempre sorprendentes, en las que Jesús veía en concreto cuál era la voluntad de $\operatorname{Dios}^{42}$.

Lo que Calcedonia expresaba en términos algo abstractos y estáticos como conjunción de dos naturalezas inconfuse et indivise en la única persona del Hijo, debe interpretarse hoy desde la perspectiva dinámica del NT que narra la vida de Jesús como plena autocomunicación del amor de Dios. Se trata de un envío, de un devenir del Hijo en la carne. Es verdaderamente el Hijo quien abandonando su condición divina se anonadó, tomó la condición humana y puso su morada entre nosotros, asumiendo plenamente nuestra condición humana.

Por eso afirma Kasper en una formulación cumbre de su obra:

Por eso, la humanidad de Jesús está unida con el Logos hipostáticamente de una manera humana, es decir, de un modo que incluye la libertad y la conciencia humana. Precisamente, al no ser Jesús otro que el Logos, es también persona humana en el Logos y por el Logos. Dicho de otra manera: la persona del Logos es la persona humana ${ }^{43}$.

Obviamente, esta afirmación no puede separarse de una concepción de persona como la que hemos expuesto y que tiene su más sólida fundamentación teológica en la comprensión del ser personal elaborada por la teología trinitaria.

42 W. Kasper, Jesús, ... 307.

43 W. Kasper, Jesús, ... 306. Subrayado nuestro. 
Las personas divinas deben su existencia y su identidad a sus mutuas relaciones subsistentes, a su mutua implicación y pertenencia perijorética. No son meras substancias individuales, autónomas, subsistentes en forma independiente cada una por sí misma. Ellas reciben y realizan eternamente su existencia como infinito intercambio de amor divino infinito. En la Trinidad, el Hijo de Dios tiene su mismo acto de ser existiendo como plena realización del amor filial, como amor de recepción y donación filial de sí, desde y hacia el Padre en la unidad del Espíritu. El Hijo, precisamente por ser aquel que tiene toda su identidad y existencia personal en la realización perfecta de esta relación de filiación, es decir, en ser el Hijo único amado del Padre, no pierde su identidad por despojarse de su condición divina y devenir hombre, para continuar existiendo como Hijo, como acto de ser de filiación pero que se dice ahora, en el ámbito de lo creado, como verdadera persona humana. "Es el acto viviente de la persona del Verbo, que pone en esta humanidad su propiedad subsistente de Hijo" ${ }^{44}$. El acto de existir como Hijo que constituye la persona del Logos, puede devenir realizándose ahora en el ámbito de lo creado, por medio de un nuevo nacimiento, que le permite existir, vivir y darse como persona plenamente humana en Jesús.

Es lo que ya sostenía A. Grillmeier cuando afirmaba que "el Logos se hizo carne, es decir, su physis una e indivisible se hizo carne y sigue siendo la misma physis única en esta realidad de la carne” ${ }^{45}$. Porque el hombre ha sido creado desde el comienzo a imagen del Hijo, es que el Hijo puede realizar su acto de existir en la naturaleza humana sin perder su identidad de Hijo único y eterno.

Sin romper la exigencia calcedónica de afirmar un único sujeto, y mantener la verdadera humanidad y la verdadera divinidad de Jesucristo, la fórmula de Kasper permite articularla no en la forma de una yuxtaposición estática, sino como comprensión dinámica del acontecer kenótico del misterio de la encarnación.

\section{UN NUEVO CONSENSO DE LA CRISTOLOGÍA CONTEMPORÁNEA}

A partir de la nueva recepción de Calcedonia, de una nueva comprensión del concepto de persona, y de una captación más integral del mis-

44 J. Moingt, El hombre... I, $134 \mathrm{~s}$.

45 "La imagen de Cristo...", 346. 
terio de la encarnación como el acontecimiento del devenir plenamente hombre del Hijo de Dios, se fue produciendo una suerte de giro copernicano en la cristología católica que permitió una consideración de la persona humana de Jesús ${ }^{46}$ más profunda, decisiva y consecuente con los testimonios bíblicos.

Este cambio fue impulsado por la fuerza de nuevas perspectivas y enfoques propios del pensamiento contemporáneo. En el contexto de una cultura y una cosmovisión distintas, que privilegian una comprensión fenomenológica, dinámica e histórica de la realidad por sobre la búsqueda de su constitución formal metafísica, era cuestión de tiempo que también en la cristología surgieran nuevas preguntas, nuevos acentos y tendencias. Es en este nuevo escenario que la cristología "hoy se plantea la cuestión de si es posible decir que Jesucristo es una persona humana” ${ }^{47}$.

En la perspectiva de la teología contemporánea, afirma Bernard Sesboüé, "sería un error muy grave si se dedujera de la ausencia de una persona humana de Cristo en el sentido antiguo, la ausencia de una personalidad humana, en el sentido moderno" ${ }^{48}$. Porque es cierto que los cristianos de hoy podrían sentirse algo "perplejos si les decimos que Jesús no era una persona humana” ${ }^{49}$.

En un mundo y una cultura que han arribado, y en gran parte igracias al propio cristianismo!, a una elevada consideración del valor inviolable de la persona humana, se haría hoy difícilmente aceptable y comprensible proclamar que el Hijo de Dios ha asumido una naturaleza humana pero no nuestra condición de personas humanas, creadas, libres, con una libertad finita y condicionada, con una conciencia y un saber finitos,

46 En el ámbito protestante el tema ya había sido más ampliamente discutido. Cf. W. Pannenberg, Fundamentos de cristología, 403-452.

47 J. O’Donnell, Introducción a la teología dogmática (Verbo Divino, Pamplona 1996) 103.

48 B. Sesboüé, "Jesus Christus aus der Sicht der Opfer. Zur Christologie von Jon Sobrino“, en Stimmen der Zeit 225 (2007) 251. En español, en versión resumida: "Jesucristo visto desde la perspectiva de las víctimas", en Selecciones de Teología 186 (2008) 119-132, 129. Si bien no queda explicado qué entiende aquí Sesboüé por "personalidad humana", el contexto pareciera sugerir que no se refiere solo a una personalidad psicológica sino más radicalmente a una plena "personeidad" humana. Por eso hablará, como vimos (cfr. supra nota 17), de una "persona humanizada”. El Dios de la salvación, 335.

49 J. O’Donnell, Introducción ... 103. 
que deben asumir la existencia que les es dada de manera agradecida, libre y responsable, pero sin estar nunca en posesión de un saber divino ilimitado, de una certeza infinita. Si sigue siendo cierto, hoy como ayer, que lo que no es asumido no es redimido, entonces también el ineludible ser persona humana que atañe a todo hombre, con todos sus límites y condicionamientos, debió ser asumido por la persona del Hijo de Dios. Se trata de una convicción teológica llamada a hacerse cada vez más profunda y difundida. Efectivamente, "esta reivindicación se impone en nuestros días con tal fuerza que muchos teólogos aceptan hablar de la persona humana de Jesús" ${ }^{50}$ asumiendo, como Walter Kasper, el desafío de mostrar cómo esa afirmación se puede conciliar con el contenido de fe que buscaban asegurar las fórmulas dogmáticas, es decir, respetando, como dijimos, la divinidad de Jesucristo y no incurriendo nunca en una duplicación de personas o sujetos de tinte nestoriano. Porque se trata siempre de una única y misma persona: la del Hijo unigénito del Padre.

Este intento de Kasper no era del todo nuevo en la teología católica. Ya Karl Rahner había avanzado mucho en esa línea,

El hombre Jesús en su realidad humana se sitúa frente a Dios como un ser absolutamente distinto, con un centro creado [...] Jesús es simplemente aquel que se recibe permanentemente del Padre y se entrega siempre a él en todas las dimensiones de su existencia [...] no puede tergiversarse en el sentido de que intrínsecamente no le corresponda [...] un centro de acción - personal, según la acepción moderna-, de autoconciencia finita y de libertad creada $[\ldots]^{51}$.

La expresión se encontraba además no solamente en P. Schoonenberg. Kasper se apoya también en M. J. Sheeben, cuando afirmaba que la humanidad de Jesús participa del "ser personal del Logos, en la medida en que ella forma una persona humana en y por él, subsistiendo así en y por él" 52 .

Pero es cierto que, una vez asumida por Kasper, la afirmación pronto se constituyó en el núcleo de un nuevo consenso de la cristología cató-

\footnotetext{
J. Moingt, El hombre ... II, 215.

Voz «Jesucristo», en Sacramentum Mundi IV (Herder, Barcelona 1973), 42, 50, 63.

52 Citado por W. Kasper, Jesús, ... 306. Subrayado nuestro. En esta línea, también deben tenerse en cuenta aquí, como antecedente importante, los aportes de W. Pannenberg. Pueden verse, sobre todo, los ya mencionados en Fundamentos de Cristología, 420-428.
} 
lica. Se trataba de un nuevo acercamiento al misterio de Cristo que, sin pretender agotarlo ni explicarlo racionalmente en una fórmula metafísica, permitía superar mejor la impresión de una cierta yuxtaposición entre una naturaleza humana y una naturaleza divina, entendidas por alguna interpretación simplista como dimensiones casi paralelas, concurrentes y difícilmente armonizables; con el peligro de convertir la naturaleza divina en una instancia material intramundana y hacer antropológicamente incomprensible la real pertenencia de la persona de Jesús a la historia del género humano. Precisamente,

[...] esa dificultad es aún mayor para nosotros, que no tenemos ya la misma antropología; para reconocer a Jesús como plenamente hombre, no nos basta con decir que tiene un cuerpo y un alma, nosotros nos sentimos obligados a reconocerle una libertad plenamente humana y autónoma, y una conciencia de sí humana e independiente, en pocas palabras: una individualidad humana completa ${ }^{53}$.

Porque como puso en evidencia J. H. Nicolas, si es cierto que: "La persona de Cristo subsiste [...] en la naturaleza humana. Una persona que subsiste en la naturaleza humana ¿es otra cosa que una persona humana?" 54 .

En la misma línea, Piero Coda comenzaría a hablar de "la Persona divino-humana de Cristo" 55 , y en coincidencia con M. Bordoni, afirmará que

[...] se puede decir entonces que «en Jesús el Verbo ha devenido, en razón de la encarnación, una persona (divina) humanizada, es decir, ha asumido en manera auténticamente humana su existencia individual y social; ha tomado su ser persona en el modo humano del devenir». Lo afirma el mismo Santo Tomás: «Verbum caro factum est, id est homo, quasi Verbum personaliter sit homo» (Quaestio disputate De unione Verbi Incarnati, a.1 $)^{56}$.

En el fondo, aquello mismo que la fórmula de la unión hipostática quería explicar en términos metafísicos, es comprendido ahora dinámicamente, en una perspectiva fenomenológica que respeta mejor la di-

53 J. MoIngt, El hombre ... I, 189.

54 Synthèse Dogmatique. De La Trinité à La Trinité. Editions Universitaires (Fribourg Suisse-Beauchesne, Paris 1985), 340.

55 "Gesù crocifisso e abbandonato e la Trinità", II, en Nuova umanità IV (1982) $24 / 25,50$.

56 "Gesù crocifisso... " 50. Piero Coda cita aquí la obra de M. Bordoni, Gesù di Nazareth, Signore e Cristo, III (Herder-PUL, Roma 1986), 848. 
mensión antropológica e histórica del acontecimiento Jesucristo requeridas por el pensamiento contemporáneo. En esa perspectiva, el misterio de la encarnación es interpretado como una verdadera humanización del Hijo de Dios y no ya como una mera anhipostasía que "despersonaliza" la humanidad de Jesús, o lo convierte en un dios que se pasea por la tierra bajo la apariencia de un hombre de Nazaret. La afirmación de la persona humana de Jesús se convirtió así en un aporte decisivo para la teología de hoy.

Esta expresión permite por otro lado refutar la objeción fundamental que ya nos habíamos encontrado: ¿cómo sería Jesús un hombre verdadero, plenamente un hombre si estuviera desprovisto de aquello que hace al valor más precioso del hombre, la personalidad? Si se responde que tiene una personalidad divina, ¿qué significa esta respuesta? ¿Es que el hombre-Jesús tiene una personalidad divina? Esto no puede entenderse más que de la manera dicha: una personalidad que tiene un hombre es una personalidad humana. Se debe decir entonces: La Persona divina, encarnándose, ha devenido una persona humana, sin cesar de ser una persona divina, la segunda persona de la Trinidad ${ }^{57}$.

El teologúmeno de la enhipostasía, para acreditarse todavía como lectura válida del misterio de la encarnación, debe comprenderse en una perspectiva que la integra como explicitación dinámica del movimiento kenótico que el Hijo eterno asume para realizar de una manera nueva su acto de existir como Hijo, como una persona plenamente humana. Existe siempre una sola persona ontológica: la persona del Hijo. No hay dos sujetos. Pero ese Hijo único, por la encarnación, asume el devenir hombre en su mismo ser, para realizar ahora su filiación única e irrepetible, en la vida, la historia y la persona del hombre Jesús.

Pero hay que decir más. Porque en Jesucristo no hay dos sujetos subsistentes y distintos en el sentido ontológico del término, el Verbo de Dios se hizo verdaderamente persona humana en Jesús. La encarnación del Hijo de Dios es una verdadera humanización [...]. El Hijo de Dios hizo suyas todas las características de la persona humana: vivió una existencia histórica y humana ${ }^{58}$.

57 J. H. Nicolas, Synthèse Dogmatique, 340. De la conclusión del párrafo se deja ver que también aquí el término personalidad es usado como equivalente de persona, como "personeidad".

58 J. Dupuis, Introducción a la Cristología (Verbo Divino, Navarra 1994), 150. 
La distinta concepción y valoración de lo que significa hoy ser persona, impulsadas en gran parte por la historia de la misma fe cristológica en un Dios relacional y trinitario, ha impulsado una nueva mirada sobre la persona histórica de Jesús. Es la misma afirmación de Calcedonia la que nos obliga a replantear cómo articular hoy, desde nuestros paradigmas conceptuales, de una manera siempre más dinámica e integral, que respete profundamente la experiencia histórica de Jesús atestiguada en el NT, la afirmación de Jesucristo como verdadero Dios y verdadero hombre, sin reduccionismos, sin mezclas, sin confusiones, y sin simplificaciones que sugieran leer la fórmula de Calcedonia como una mera yuxtaposición abstracta de naturalezas.

El recorrido hecho hasta aquí y los autores citados han servido para mostrar este nuevo consenso cristológico de la teología contemporánea. Pero eso no legitima, claro está, el descuido de caer en el error contrario. No se trata de negar u olvidar ahora la verdadera divinidad ontológica de Jesús, ni de reducirlo a un mero mártir más de la historia de la humanidad. Por el contrario, "Jesús, en efecto, más que cualquier otra persona, fue una personalidad completamente original: en él el Hijo de Dios hizo personalmente la experiencia del vivir humano en el acontecer histórico" 59 . Solo él es nuestro Salvador. Él y solo él es el Hijo único del Padre. Es verdaderamente una persona divina, la del Hijo eterno del Padre, la que ha devenido persona verdaderamente humana en el hombre Jesús. De tal manera, que también la personalidad humana psicológica de Jesús está marcada, en virtud de su mismo origen e identidad, por ser la libertad y la autoconciencia humana del mismísimo Hijo de $\operatorname{Dios}^{60}$.

Es así, que una nueva recepción del contenido y significado del mismo dogma cristológico expresado "en los esquemas del pensamiento con-

59 J. Dupuis, Introducción a la Cristología, 150.

60 Cf. G. EssEn, Die Freiheit Jesu, 260-315. Es en ese sentido metafísico es que puede afirmarse que Jesús "existe de una forma distinta que los demás seres humanos, a saber, gracias al mismo Logos y no solo en virtud de un acto creativo distinguible de Dios que constituye una hipóstasis humana distinta de Dios". M. Shultz, "Subjetividad, autoconciencia y conocimiento de Jesús", en A. Cordovilla - J.M. Sánchez Caro - S. Del Cura Elena (eds.), Dios y el hombre en Cristo (Sígueme, Salamanca 2006), 401. No se trata de un mero "acto de creación" de algo distinto, sino de la misma hipóstasis del Hijo, que sin perder su identidad ahora comienza a realizar su acto de existir como Hijo en una hipóstasis humana creada, verdaderamente nacida, de María. 
temporáneo, nos permite afirmar que Jesús es una persona humana" ${ }^{61}$, y hacerlo en estricta fidelidad y continuidad con la fe de la Iglesia en la plena divinidad y humanidad de Jesucristo, como un único sujeto, una única persona, un único Hijo de Dios. La claridad y contundencia con que lo expresara el cardenal Kasper, significó -para lograrlo- un impulso invalorable. Es un reconocimiento obligado al cumplirse 40 años de la aparición de su memorable Jesús, el Cristo.

${ }_{61}$ J. O’Donnell, Introducción ..., 105. 
